\title{
Disturbance-robust Current Control Technique for Large-scale PV Inverter
}

\author{
Tomomichi Ito ${ }^{* a)} \quad$ Member, $\quad$ Akira Kikuchi* ${ }^{*} \quad$ Member \\ Masahiro Taniguchi* Non-member, Yoshitaka Takemoto* Non-member \\ Masaya Ichinose* Member
}

(Manuscript received April 17, 2018, revised Oct. 9, 2018)

\begin{abstract}
A disturbance-robust current control technique for large-scale PV inverter whose rating is several hundred $\mathrm{kW}$ is described. The biggest disturbance against current control of grid-connected inverters is the grid fault. The goal of this development is set as to be able to ride through three-phase grounding faults whose residual voltage is down to zero. The main development point of the scheme is to introduce sophisticated voltage feedforward control and improved sampling technique in the current control system. The idea is to make the AC output voltage of the IGBT assemblies follow the quick change in the grid voltage with a small time delay in order to reduce the AC current overshoot caused by grid faults. The validity of the control scheme is confirmed by a simulation study and full-load fault-ride-through tests.
\end{abstract}

Keywords: PV inverter, Fault ride through, gate blocking

\section{Introduction}

Today's grid-connected renewable energy sources (RESs) play a role in keeping stable electric power supply because large scale integration of RESs in the power system never allows us to deal with the RES as negligible generators from the view point of demand and supply balance. The role in power system requires RESs to have fault-ride-through (FRT) capability. Most of today's RESs have inverter interface against grid. In such RESs, FRT function is realized by inverter control.

FRT requirements differ by countries or transmission system operators ${ }^{(1)(2)}$. But normally, the FRT requirement is not to allow RESs disconnected during the voltage dip caused by grid fault. Some grid codes require reactive current supply from the RESs to make RESs contribute to keep grid voltage $^{(3)}$.

Inverters experience large grid voltage changes at the beginning and at the end of grid fault. Large current disturbances in the inverter output current occur at that timings.

Disconnection from the grid is thought to open AC circuit breakers or contactors. So, short time gate blockings (hereinafter, referred to as GB) to protect the semiconductor devices in the inverter at the beginning of grid fault and at the recovery of the fault are allowed if the mechanical switches as breakers and contactors are on. However, GB at the end of grid fault can cause sharp and large voltage rise at the grid because of large $d i / d t$ caused by GB. Other systems connected to the same grid may stop its operation by detecting the large

a) Correspondence to: Tomomichi Ito. E-mail: tomomicih.ito.wd @ hitachi.co.jp

${ }^{*}$ Hitachi, Ltd.

7-2-1, Omika-cho, Hitachi-shi, Ibaraki 319-1292, Japan grid voltage. From this meaning, it is desirable to be able to ride through grid faults without GB.

Japan modified its grid code on grid-connected PV inverters and activated in 2017. The new code prohibits the inverters to have GB during grid faults with symmetric grid voltage changes whose residual voltages are larger than $20 \%$ of its nominal values ${ }^{(4)(5)}$. So, the FRT capability without GB is required not only from technical reason but also from business aspects of PV plant owners.

Concerning FRT techniques, discussion of grid-side impact $^{(6)(7)}$, and protection of wind turbines ${ }^{(8)-(10)}$ are frequently discussed. When it comes to FRT technique for PV inverters, coordination technique of FRT and MPPT control are well discussed $^{(11)-(14)}$. Especially, PV inverters with boost chopper circuit requires special attention on DC-link voltage control. Literatures (12) and (14) focus on the prevention technique of low voltage or over voltage at DC-link circuit. Literature (13) introduces current control strategy based on positive and negative sequence components. However, not so many papers describe PV inverter's current control scheme to ride through grid fault without GB can be found.

Disturbance suppression technique based on observerbased control and repetitive control are frequently discussed in motor drive applications ${ }^{(15)-(17)}$, but the techniques are not suitable to suppress the transient phenomena. State feedback control is one of the best ways to design the reaction speed of the control against disturbance. But the control sometimes brings unexpected results because of large ripple current in the LC harmonic filter circuit.

Furthermore, it is not easy to comply with the requirement in case of high power inverter because the switching frequency of the inverter is limited at a few $\mathrm{kHz}$ from efficiency requirement. With low switching frequency, chances 
to change the duty ratio of IGBTs gets less and time delay at the voltage output stage gets longer. To make the matter worse, when the inverter has 3-level configuration, the output voltage of the IGBT assembly contains smaller harmonics than the voltage of 2-level inverter. The optimal design of the harmonic filter circuit for 3-level inverter makes the inductance of the filter reactor quite small, which results in sharp current increase at grid faults. The output current gets larger than protection level within a few hundred micro seconds. It is required to make the inverter react as quickly as possible by considering the hardware limitation explained above.

In this paper, current control technique to reduce current increase caused by grid voltage change is described. This technique is especially effective for a few-hundred $\mathrm{kW}$ inverter system.

Section 2 explains the inverter under discussion and challenges in realizing FRT without GB with a few-hundred $\mathrm{kW}$ inverter. Section 3 gives the idea how to realize FRT without GB and concrete control efforts. Simulation and full-load test results of FRT are explained in Section 4, and the discussion is summarized in Section 5.

\section{Inverter under Discussion and Challenges}

2.1 Inverter under Discussion As a target inverter, 660-kW PV inverter is chosen here. Figure 1 shows the overview of the inverter and Table 1 shows its main specifications.

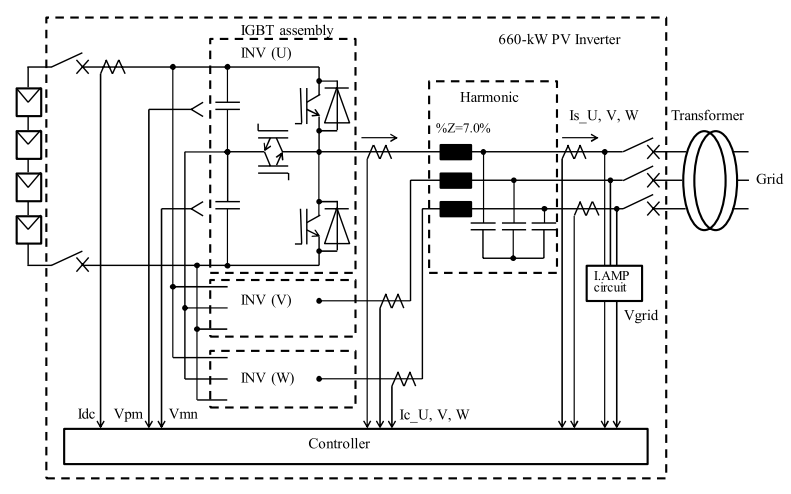

Fig. 1. Overview of the inverter under discussion

Table 1. Specifications of the inverter under discussion

\begin{tabular}{|c|c|c|}
\hline Items & Numbers & Remarks \\
\hline Rated capacity & $2660 \mathrm{~kW} / 690 \mathrm{kVA}$ & \\
\hline Rated AC voltage & $360 \mathrm{~V}$ & $\begin{array}{l}\text { Line-to-line r.m.s. } \\
\text { value }\end{array}$ \\
\hline Rated AC current & $1107 \mathrm{~A}$ & r.m.s. value \\
\hline Rated grid freq. & $50 / 60 \mathrm{~Hz}$ & \\
\hline $\begin{array}{c}\text { Operational range } \\
\text { of input voltage }\end{array}$ & $520-900 \mathrm{Vdc}$ & $\begin{array}{c}\text { MPPT operational } \\
\text { range }\end{array}$ \\
\hline Topology & 3 level inverter & $\begin{array}{c}\text { With reverse } \\
\text { voltage blocking } \\
\text { IGBTs }\end{array}$ \\
\hline Configuration & Single stage & \\
\hline Max. efficiency & $98.8 \%$ & Input: DC520V \\
\hline Filter circuit & L-C filter circuit & $\begin{array}{l}\% Z \text { of the filter } \\
\text { reactor is } 7 \%\end{array}$ \\
\hline $\begin{array}{l}\text { Impedance of grid- } \\
\text { connecting trans. }\end{array}$ & $3.8 \%$ & 690 kVA base \\
\hline $\begin{array}{c}\text { Overcurrent } \\
\text { detection level }\end{array}$ & $2269 \mathrm{Ap}$ & $\begin{array}{c}145 \% \text { of rated } \mathrm{AC} \\
\text { current }\end{array}$ \\
\hline
\end{tabular}

Needless to say, efficiency is one of the most important characteristics of PV inverters. Especially, high-power inverters are expected to have better efficiency compared to small-scale inverters. To achieve high efficiency, the inverter has three-level topology with reverse voltage blocking IGBTs.

Compared to conventional two level inverter, the output voltage of the IGBT assembly is close to sinusoidal. This feature enables us to lower the switching frequency of the inverter. The harmonic filter is also optimized and its impedance is much smaller than the filter circuit required in two level configuration.

Voltage sensors and current sensors are installed at AC connecting point of the inverter and additional current sensors for over current protection are installed at the output terminals of IGBT assemblies. In this system, the detection level of the overcurrent protection is $145 \%$ of nominal current.

Figure 2(a) shows the overall of the inverter's control function and (b) shows the details of current control.

Measured value of DC input current and DC input voltage are fed into MPPT calculation block and it gives DC voltage reference Vdc*. DC-AVR, which is a regulator of DC-link voltage, inputs the deviation of the reference and total DClink voltage, and calculates active current reference signal. Power factor control is realized by reactive power reference depending on the set point of power factor cos $\eta$ and reactive power control. The reactive power control gives reactive current reference to match the reference and feedback of the reactive power.

Phase detector calculates grid voltage phase. Synchronous signals for $\mathrm{d}-\mathrm{q}$ transformation and reverse $\mathrm{d}-\mathrm{q}$ transformation are calculated by using the phase.

Balancing of DC voltages Vpm and Vmn is realized by Voltage balancing controller which gives correction signal $\Delta V$ of AC voltage references.

Current control mainly consists of voltage feed forward

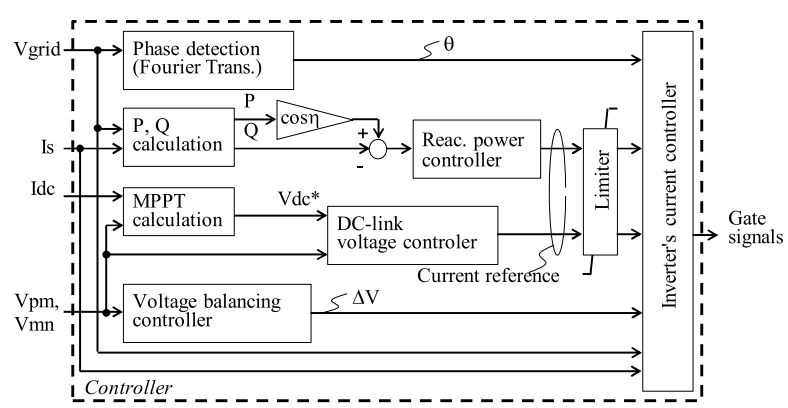

(a) Overview of the control function

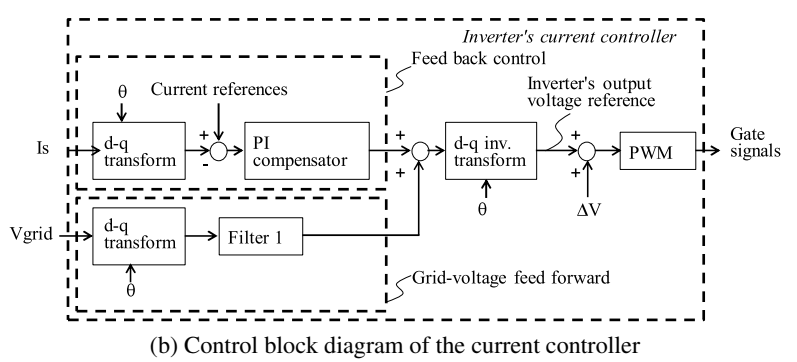

Fig. 2. Overview and detailed control block diagram of the inverter 


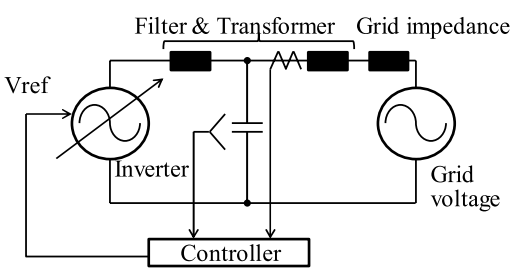

(a) Voltage balance at normal condition

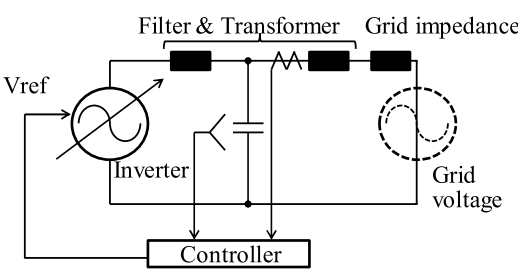

(b) Disturbance caused by grid fault

Fig. 3. Image to tell the grid fault impact on current control

part and feedback control part. The aim of the voltage feed forward is to let the IGBT assemblies output the same voltage as grid voltage. Feedback part calculates the corrective voltage reference to flow active and reactive current match their references.

As the controller requires finite calculation time and the PWM looks as sample and hold block, there is time delay in the output voltage compared with the voltage reference. If voltage feed forward part just gives the sensed grid voltage as output voltage reference, low order harmonic current can be increased a bit because the harmonic components in the output voltage have phase difference from the harmonic voltage at grid side because of the time delay. Low-pass filter "Filter 1 " is installed to avoid the small harmonic amplification.

2.2 Target Values and Challenges As explained, current control of the inverter is realized by balancing the grid voltage and output voltage of the IGBT assembly. Figure 3 shows the image of the current control. By outputting AC voltage, which is summation of grid voltage and voltage drop occurs at the harmonic filter circuit, the transformer, and the grid impedance from the IGBT assembly, the inverter can output desired current. When a grid fault occurs, the grid voltage changes significantly and instantaneously. This voltage change becomes big disturbance on the current control system and the fault current appears just after the grid fault is limited by the impedance of filter circuit, transformer, and the grid impedance. From this reason, the grid fault in the vicinity of the grid-connecting transformer is the most severe one for the inverter.

Three-line grounding fault (3LG) nearby the grid-connecting transformer gives the biggest disturbance on the current control because the residual grid voltage is zero.

Figure 4(a) shows the simplified model of the current response against grid faults. This is a DC circuit model has the same inductance and capacitance as the harmonic filter circuit has, inductance which is equal to the leakage inductance seen from the inverter. To assume the most severe case, inductance at grid side Lsys is set as zero. Figure 4(b) shows the simulation result. The graph shows the waveforms of grid current Is, assembly current Ic, and acceptable current increase. By assuming that the grid fault occurs when the phase current has its top during rated power operation, acceptable current

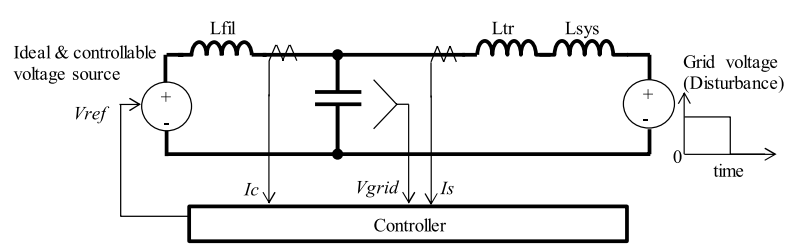

(a) Simplified DC model of current control disturbance evaluation

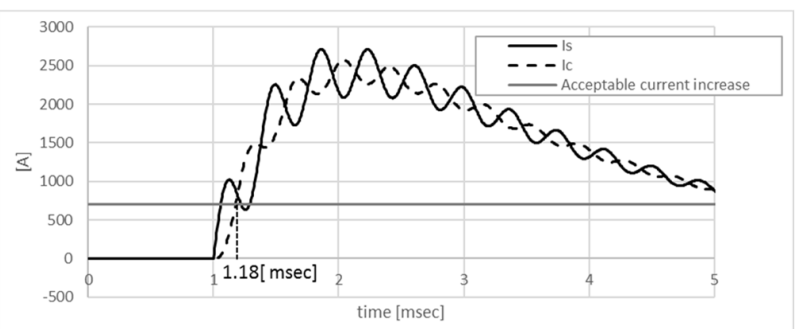

(b) Simulation results of the simplified DC model

Fig. 4. Simulation model and results of the simplified DC model to evaluate current disturbance caused by grid fault

increase is $45 \%$ of rated current.

At $\mathrm{t}=1$ [msec], the grid voltage fell down to zero. Only within 0.18 [msec], assembly output current $I c$ exceeds the acceptable current increase. This is because the optimized harmonic filter for three-level topology has small inductance. To make the matter worse, the update timing of the IGBT assemblies' output voltage reference is delayed by half of PWM carrier period, which is longer than 0.1 [msec].

So, the target and challenge of this study is to reduce the rapidly increased current caused by $3 \mathrm{LG}$ lower than $45 \%$ of rated current with $660-\mathrm{kW}$ inverter's hardware limitations.

\section{Realization of FRT without GB}

In this section, the main ideas to realize FRT capability without GB are given and detailed explanations follows.

3.1 Main Ideas to Realize FRT without GB Section 2 explained that the balancing of grid voltage and IGBT assemblies' output voltage decides the grid current, and the current increase caused by grid fault can exceed the OC detecting threshold within only 0.18 [msec]. A key to solve the problem is how fast the voltage balancing can be established at the beginning and at the end of the grid fault. The fast establishment of voltage balancing enables us to reduce current increase caused by grid faults.

Table 2 summarizes the idea to achieve fast voltage balancing. The idea consists of three improving. The next section gives the detailed explanations one by one.

\subsection{Countermeasures to Realize FRT without GB}

(i) Sampling timing control

Output current in the inverter contains ripple current

Table 2. Summary of the ideas to realize FRT without GB

\begin{tabular}{|c|c|}
\hline Ideas & Expected effects \\
\hline \hline Sampling timing control & $\begin{array}{c}\text { To shorten the time delay in the } \\
\text { voltage updating }\end{array}$ \\
\hline $\begin{array}{c}\text { Switching the time constant } \\
\text { of voltage feed-forward part }\end{array}$ & To achieve quick voltage \\
balancing
\end{tabular}




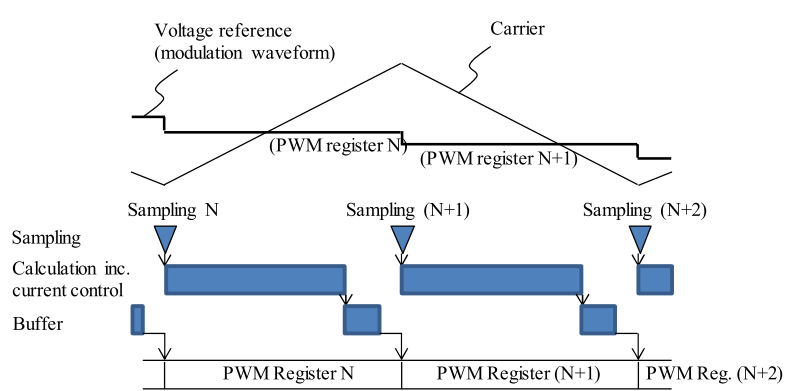

(a) Conventional sampling and updating the voltage reference

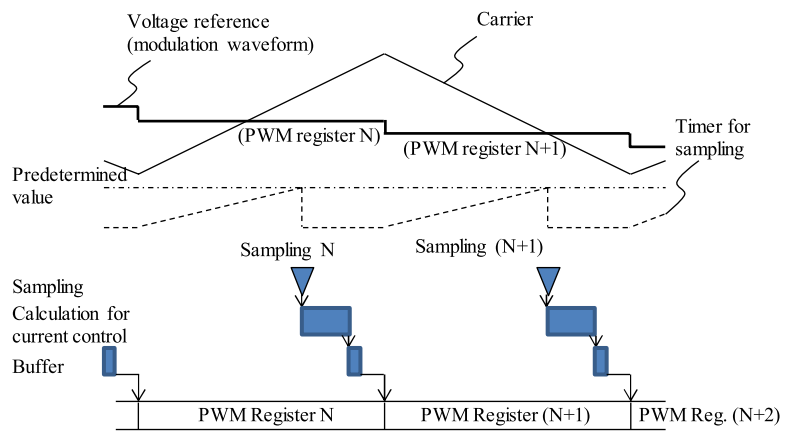

(b) Improved sampling timing and updating the voltage reference

Fig. 5. Improved sampling to shorten the time delay

caused by PWM. To make the ripple component in the sensed current value small, it is desired to sample the current when the carrier reaches its peak or bottom in case of PWM with triangular wave carrier. To avoid multiple switching within half period of PWM carrier, updating timing of the voltage reference should be set at the peak or bottom of the carrier.

Figure 5(a) explains the sampling and PWM register updating process of conventional current control. When the PWM carrier gets at its peak or bottom, trigger for sampling is generated. After the sampling, calculation process including current control starts. After finishing the calculation, voltage reference for next half carrier period is set on the buffer register. When the carrier gets its top or bottom, the value stored in the buffer register is transferred to the PWM register. In the process, time delay from sampling to updating the voltage reference update is half of the PWM carrier period.

Normally, carrier frequency of several-hundred $\mathrm{kW}$ inverter is a few $\mathrm{kHz}$. Assembly current increase exceeds the acceptable level within only 0.18 [msec] as shown in Fig. 4. So, the delay of the half of the PWM carrier period can be never ignored.

However, by executing current control not on the IGBT assembly current but on the grid-side current, sampling timing can be changed without any fear of ripple current sensing because the harmonic filter circuit absorbs most of the ripple current in the IGBT assembly current. Moreover, as shown in Fig. 4, current increase caused by the grid fault appears in the grid-side current much faster than in the assembly output current. So, it's better to implement current control on the grid-side current to avoid GB.

Realization to shorten the time delay is explained in Fig. 5(b). By preparing a timer which starts count up at the peak or bottom of the carrier, state variables' sampling synchronized with carrier can be achieved. When the timer counts up and the counter matches the predetermined value,

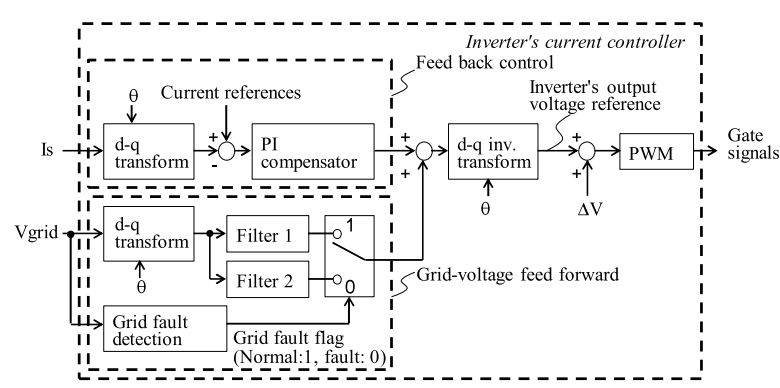

Fig. 6. Current control with improved feed-forward control

trigger for sampling is generated. Proper setting of the trigger level enables us to minimize the time delay from sampling to update of the voltage reference.

(ii) Switching the time constant of voltage feed forward part

Figure 6 shows the current control with improved feed forward control.

As described at 2.1, low-pass filter is installed in the feedforward part in the current control system to reduce the slight increase of harmonic current. During the grid fault, it's much important to make the voltage reference follow the quick change in the grid voltage in order to avoid large current disturbance compared to reduce slight increase of the harmonic current.

By installing a grid-fault detection block and changing the time constant of the low-pass filter during the grid fault, the IGBT assembly can output voltage with small deviation from the grid voltage and the current increase can be made small. The grid-fault detection block inputs sensed grid voltages and calculates the amplitude of grid voltage. When the amplitude gets smaller than predetermined value, the detection block changes its output, Grid fault flag, from 1 to 0 . The flag is sent to the switch that inputs two outputs from Filter 1 and Filter 2. Output of the switch is controlled by the Grid fault flag. When the flag is 1 , it means the grid voltage is sound and the output of Filter 1 is chosen as output of the switch. When the flag is 0 , that means there is a grid fault. The output of Filter 2, whose time constant is shorter than Filter 1, is chosen as output of the switch. With this configuration, fast reaction of the inverter against the grid fault and low harmonic current during normal operation can be realized at the same time.

Feed forward of the grid voltage affects current control's stability margin as explained in detailed at the next chapter. The impact on the stability is dependent on grid impedance. So, the time constants of Figs. 1 and 2 shall be designed together with current control gains by considering the maximum grid impedance to be expected.

(iii) Optimization of current control gains

The last idea is to optimize the current control gains. Even if the feed-forward voltage follows the grid voltage change perfectly, the inverter experiences current disturbance because of the resonance caused by grid impedance and the filter capacitor. So, feed-back part also have to optimized.

Large feed-back control gains can reduce the current increase caused by disturbance. But, at the same time, the gain and phase margins in the current feedback control are reduced. Optimization of the control gains is achieved by 


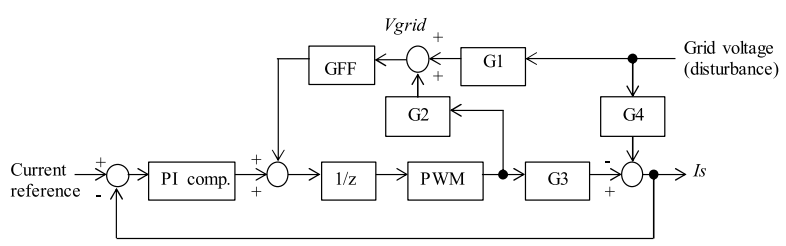

Fig. 7. Total transfer function of the current control system

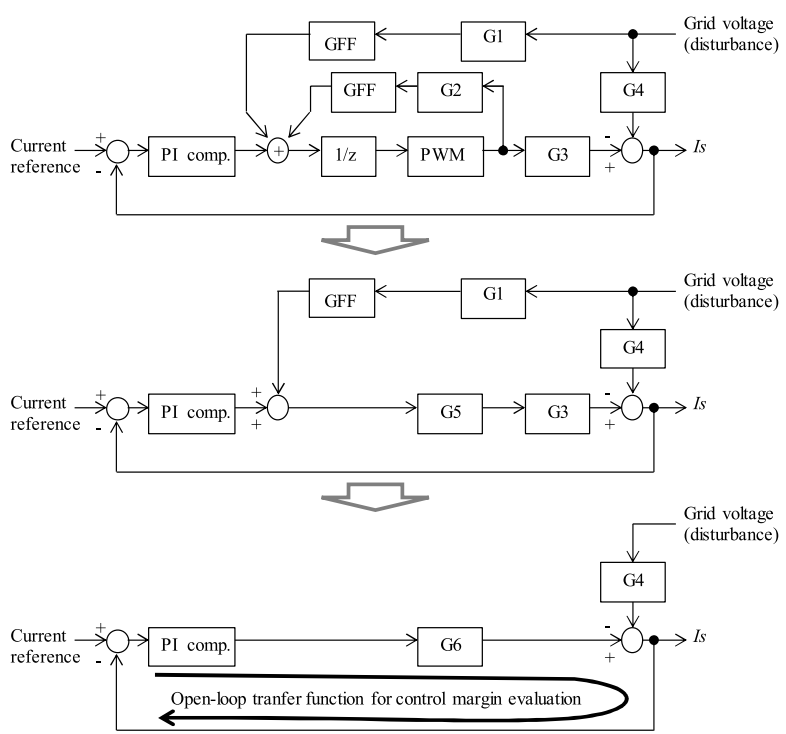

Fig. 8. Derivation of open-loop transfer function of the current control system

choosing large control gains, leave suitable control margins.

Evaluation of control margins requires derivation of openloop transfer function. Figure 7 shows the total transfer function of the current control system. Sum of the outputs of feed-back part and feed-forward part is an input of calculation delay $1 / z$ and PWM. As explained, the delay is shortened with the idea shown in Fig. 5(b).

PWM can be treated as Sample \& Hold block whose holding period is half of the carrier period because the voltage reference is updated only at the peak or bottom of the carrier. Output of the PWM block is the output voltage of the IGBT assembly. Grid voltage which the inverter can detect is the filter capacitor voltage. The voltage Vgrid appears across the harmonic filter capacitor is affected by both grid voltage and assembly output voltage. Transfer functions G1 to G4 are given in equation (1).

$$
\left\{\begin{array}{c}
G_{1}=\frac{Z_{L f i l} / / Z_{C f i l}}{\left(Z_{L f i l} / / Z_{C f i l}\right)+Z_{t r}+Z_{s y s}} \\
G_{2}=\frac{Z_{C f i l} / /\left(Z_{t r}+Z_{s y s}\right)}{Z_{L f i l}+Z_{C f i l} / /\left(Z_{t r}+Z_{s y s}\right)} \\
G_{3}=\frac{1}{Z_{L f i l}+Z_{C f i l} / /\left(Z_{t r}+Z_{s y s}\right)} \cdot \frac{Z_{C f i l}}{Z_{C f i l}+Z_{t r}+Z_{s y s}} \\
G_{4}=\frac{1}{Z_{t r}+Z_{s y s}+Z_{L f i l} / / Z_{C f i l}}
\end{array}\right.
$$

where $Z_{L f i l}$ is the impedance of filter reactor, $Z_{C \text { fil }}$ is the impedance of filter capacitor, $Z_{t r}$ is the impedance of transformer seen from the inverter, and $\mathrm{Z}_{\mathrm{sys}}$ is the grid impedance seen from the inverter. Physical meaning of the transfer function in equation (1) is as shown below.

AC voltage appears at filter capacitor Vgrid is determined not only by grid voltage but also by assembly output voltage. The coefficients of grid voltage and assembly output voltage on Vgrid are represented as $\mathrm{G}_{1}$ and $\mathrm{G}_{2}$. AC output current of the inverter $I s$ is also calculated by grid voltage and assembly output voltage. The admittance from grid voltage to $I s$ is represented as $\mathrm{G}_{4}$ and the admittance from assembly output voltage to $I s$ is represented as $\mathrm{G}_{3}$.

By following the arrangement shown in Fig. 8, the control loop with several feedback loop can be simplified and open-loop transfer function can be gotten. With the openloop transfer function, large gains with the control margin can be selected.

\section{Evaluation of the FRT Capability without GB}

Simulation study and experiments were carried out to check the validity of the ideas for FRT without GB. This chapter firstly shows the simulation result. After that, set-up and results of full-load FRT test are given.

4.1 Simulation Study to Evaluate the Control Function Simulation study was carried out to check if the idea shown in the last chapter can really work. Simulation model shown in Fig. 9 was created. DC inputs of the inverter are connected to a DC voltage source and the controllable AC voltage plays the role of grid voltage. The switching frequency, filter circuit parameters, sampling timing, time delay for calculation, and characteristics of analogue filters were modeled as the real inverter has.

In a reality, the inverter operates with MPPT function. However, the active current reference is kept at its rated value in this simulation to evaluate the disturbance on current control caused by voltage disturbance.

As grid condition, it was assumed that the grid fault occurred in vicinity of the transformer and the ground fault impedance was set as almost zero. Figure 10 shows the simulation result. The graph shows grid voltage Vsys_U, Vsys_V, $V s y s_{-} W, \mathrm{AC}$ voltage of the PV inverter $V g_{-} U, V g_{-} V, V g_{-} W$, grid current $I s_{-} U, I s_{-} V, I s_{-} W$, and assembly output current $I c_{-} U, I c_{-} V, I c_{-} W$ from the top. The $\mathrm{PV}$ inverter outputs its rated output power at the power factor of unity.

The grid fault occurs at $\mathrm{t}=0.04$ [sec] when the grid phase voltage Vsys_U has its peak. This is the most severe condition for the inverter to ride through the fault without GB because

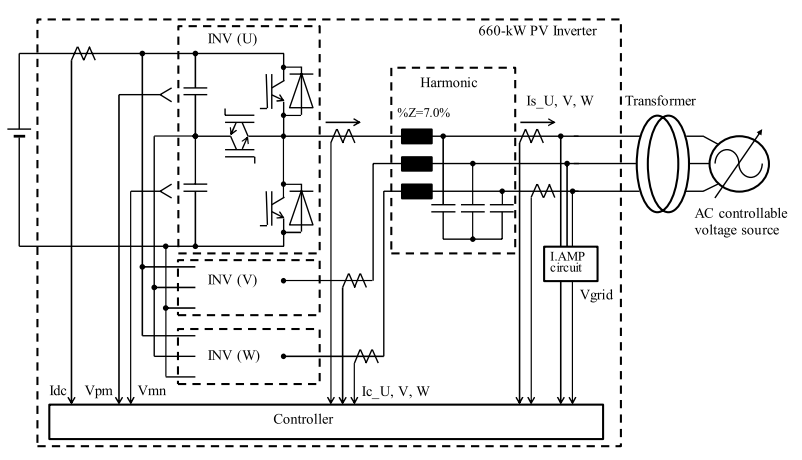

Fig. 9. Simulation model for FRT capability evaluation 


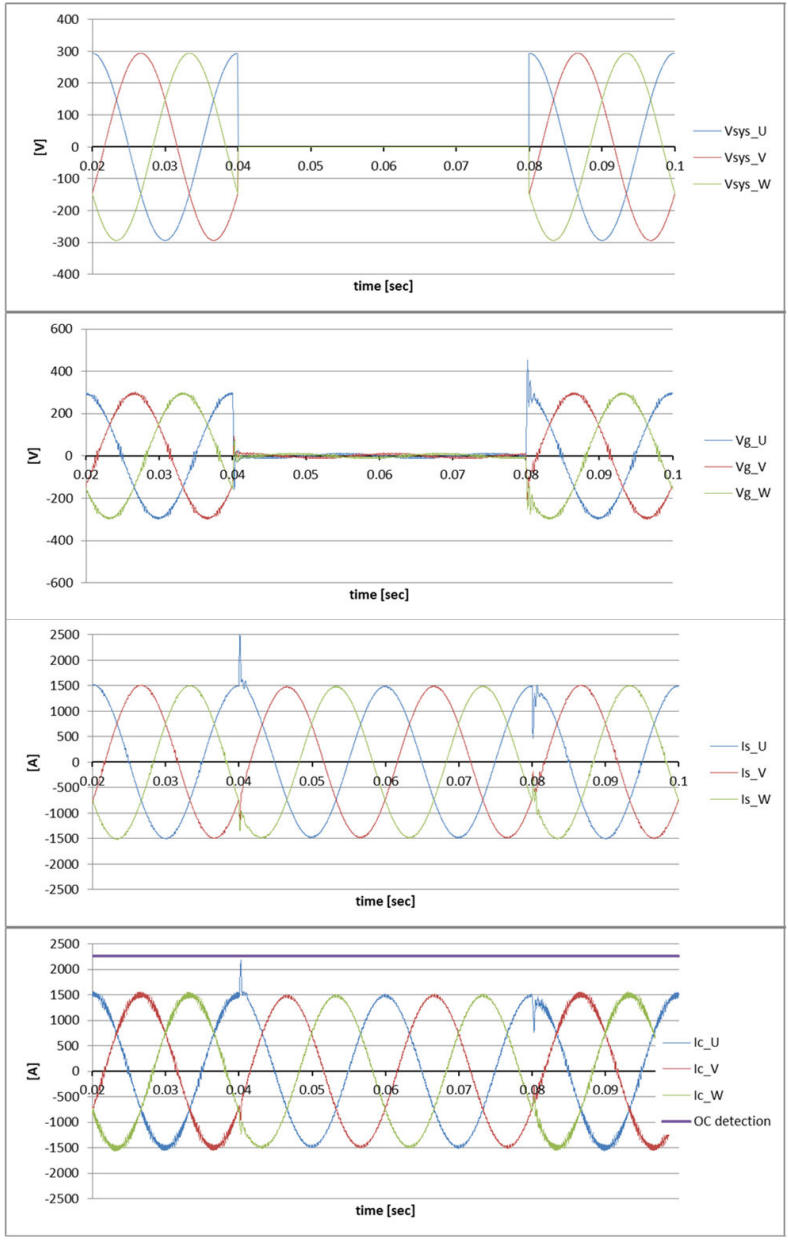

Fig. 10. Simulation result assuming 3LG nearby the inverter the assembly output current $I c_{-} U$ has its peak value and the voltage drop causes significant increase in the assembly output current.

The simulation result says that the peak value of assembly current $I c_{-} U$ is suppressed at $2148 \mathrm{~A}$ which is lower than over current detection level (2269 A), and the inverter can ridethrough the grid fault without GB even at the most severe case. Peak value of grid current $I s_{-} U$ is larger than assembly current $I c_{-} U$. This is because of the discharging current of the filter capacitor installed in the inverter's harmonic filter circuit.

\subsection{Experimental Evaluation with full-load FRT}

Full-load FRT experiment was carried out to confirm the validity of the current control and simulation. Figure 11 shows the test setup. Input DC power is supplied by a DC voltage source and resistor circuit simulates the movement of solar panels. The inverter under test is connected to an AC controllable voltage source via the transformer.

Instead of making short circuit, the output voltage of the AC controllable voltage source was changed in step wise.

Rated power of the AC controllable voltage source is 5 MVA and it's big enough to evaluate the inverter's reaction

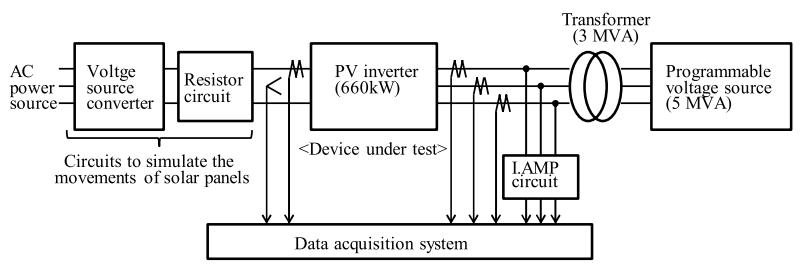

Fig. 11. Full-load FRT test setup
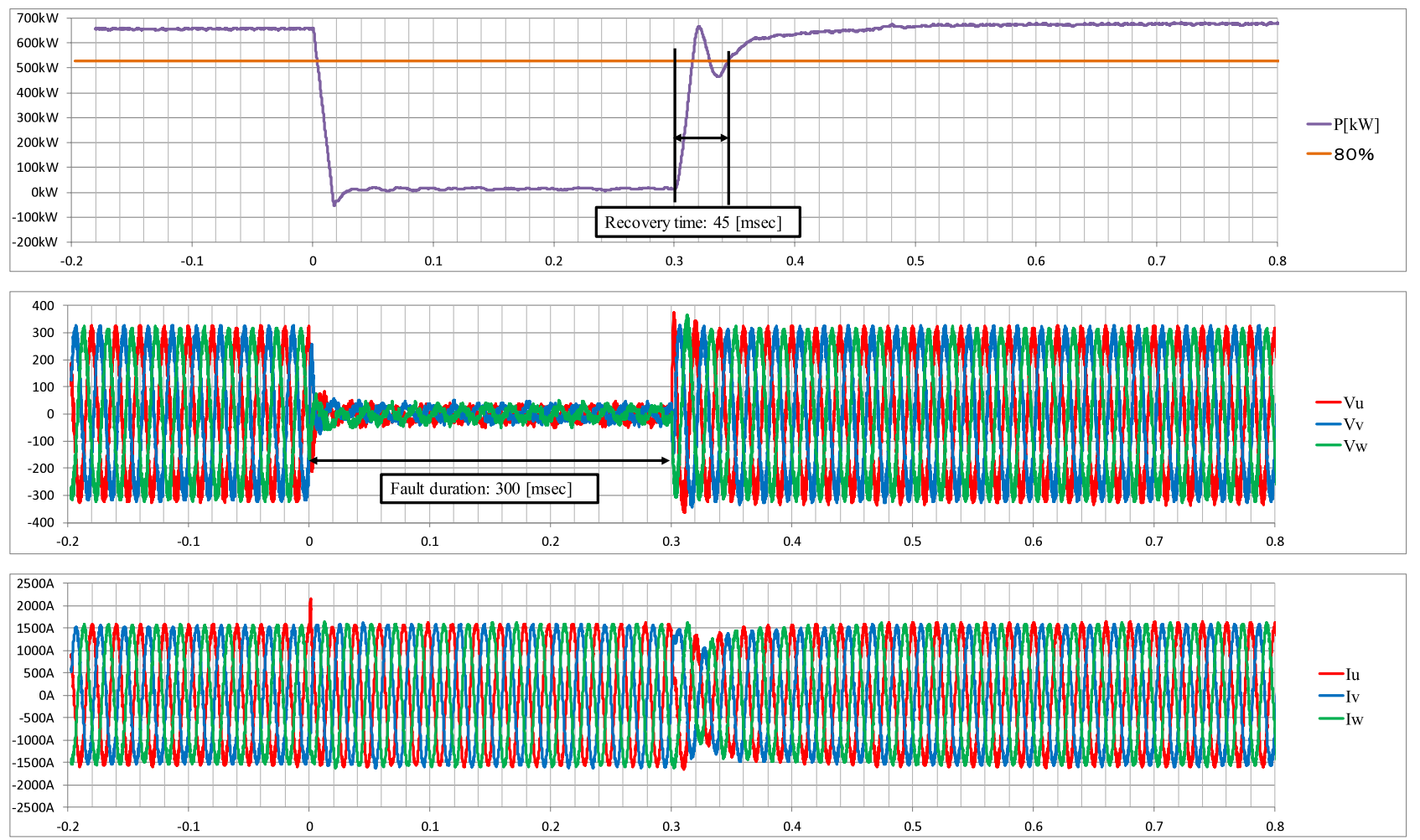

Fig. 12. Test result of full-load FRT

Operational condition: Rated power $(660 \mathrm{~kW}), \mathrm{PF}=1$

Timing of grid voltage fall: at when phase voltage in $U$ phase has its peak 
against sudden voltage changes. The AC controllable voltage source can control its output voltage with the time constant of shorter than $2 \mathrm{msec}$. Not only the voltage magnitude but also the start timing of voltage dip, timing of recovery, and time length of the voltage dip can be programmed in the voltage source. With this control function, the most severe condition as created in simulation study can be realized.

Figure 12 shows one of the full-load FRT test. The graph shows the waveforms of AC output power of the inverter, line-to-line grid voltage at the secondary side of the gridconnection transformer and $\mathrm{AC}$ output current of the inverter from the top. Overcurrent detection level of the inverter is $2269 \mathrm{~A}$ as shown above. The inverter outputs its rated power of $660 \mathrm{~kW}$ before the voltage drop.

Grid voltage fell from $100 \%$ to $0 \%$ at $0.0 \mathrm{sec}$. and recovered at $0.3 \mathrm{sec}$. Phase voltage of the grid voltage in phase $\mathrm{U}$ has its peak and the grid current $I s_{-} U$ also has its peak at $0.0 \mathrm{sec}$.

Phase current $I s_{-} U$ increases when the grid voltage drops as in the simulation result shown in Fig. 10. It can be confirmed that the inverter continues outputting AC current to the grid without GB even at the most severe condition.

The figure also tells that the output power from the inverter recovered quickly after the voltage drop and the recovery time, that is the time delay till the power recovers over $80 \%$ of its output power just before the voltage drops, is only 45 [msec].

It's seen that grid voltage still has small value even during the voltage dip. This is because of the voltage drop appears between grid-connecting transformer and power cables connect the transformer and the controllable AC voltage source.

Short-time current decrease after the voltage recovery can be found. This is because the current reference, calculated by MPPT, changed.

\section{Summary}

This paper proposes a current control scheme for grid connected inverter which is relatively large-scale one. The goal is to ride through the grid fault without gate blocking of the inverter.

The current increase appears at the output current of the inverter when the grid voltage drops and recovers. This is due to the disturbance on the current control system.

The main development points of the scheme are to introduce sophisticated voltage feed forward control and improved sampling in current control system. With these ideas, inverter's output voltage can follow quick change in the grid voltage and the current increase at the grid voltage changes can be suppressed.

Simulation model was created to evaluate the current control function and the full-load FRT experiment was also conducted to show the validity of the proposed control scheme.

Both of simulation result and experimental result show that the inverter whose rating is $660 \mathrm{~kW}$ can ride through the grid fault even if the voltage changing timing is the worst one.

\section{References}

( 1 ) TRANSPOWER New Zealand: "Generator Fault Ride Through (FRT) Investigation-Stage 1 Literature Review”, Version 2, pp.32-36 (2009)
( 2 ) Y. Mitani, N. Tokuda, and H. Kobayashi: "Present status of large-scale integration of renewable energy sources and countermeasures against the issues", IEEJ Journal, Vol.138, No.2, pp.74-77 (2018) (in Japanese)

( 3 ) D. Gao, E. Muljadi, et al.: "Comparison of Standards and Technical Requirements of Grid-Connected Wind Power Plants in China and the United States", NREL Technical Report, NREL/TP-5D00-64225, pp.26-27, 32 (2016)

( 4 ) Japanese Grid-interconnection Code JEAC 9701-2012, addendum-2014No.2 (2014)

( 5 ) Japanese Grid-interconnection Code, JEAC 9701-2016 (2016)

( 6 ) I. Ngamroo: "Review of DFI Wind Turbine Impact on Power System Dynamic Performances", IEEJ Transactions on electrical and electronic engineering Vol.12, pp.301-311 (2017)

( 7 ) D. Tu, S. Chaitusaney, and A. Yokoyama: "Fault Current Calculation in Distribution Systems with Inverter-Based Distributed Generations", IEEJ Transactions on Electrical and Electronic Engineering, Vol.8, pp.470-477 (2013)

( 8 ) M. Cheng, S. Kato, and R. Shimada: "A Novel Method to Improve LowVoltage Ride-Through Capability of Wind Turbine Generators", IEEJ Transactions on Electrical and Electronic Engineering, Vol.8, pp.522-528 (2013)

( 9 ) A. Thet and H. Saitoh: "Pitch Control Based on Voltage Dip Detection for Improving the LVRT of Wind Farm", IEEJ Transactions on Electrical and Electronic Engineering, Vol.7, pp.136-143 (2012)

(10) N. Tong, S. He, X. Lin, et al.: "RBFNN-Based Adaptive Crowbar Protection Scheme Designed for the Doubly fed Induction Generator in Large-Scale Wind Farms", IEEJ Transactions on Electrical and Electronic Engineering, Vol.10, pp.644-652 (2015)

(11) C.H. Benz, W.-T. Franke, and F.W. Fuchs: "Low Voltage Ride Through Capability of $5 \mathrm{~kW}$ Grid-Tied Solar Inverter", $14^{\text {th }}$ International Power Electronics and Motion Control Conference, EPE-PEMC 2010, pp.T12-13-T12-20 (2010)

(12) G. Md. Saeedul Islam, A. Al-Durra, et al.: "Low Voltage Ride Through Capability Enhancement of Grid Connected Large Scale Photovoltaic System", IECON 2011-37 th Annual Conference on IEEE Industrial Electronics Society, pp.884-889 (2011)

(13) X. Bao, P. Tan, et al.: "Low Voltage Ride Through Control Strategy for HighPower Grid-Connected Photovoltaic Inverter", Applied Power Electronics0 Conference and Exposition (APEC), $201328^{\text {th }}$ Annual IEEE Conference, pp.97-100 (2013)

(14) C.-Y. Tang, Y.-T. Chen, and Y.-M. Chen: "PV Power System With MultiMode Operation and Low-Voltage Ride-Through Capability", IEEE Transactions on Industrial Electronics, Vol.62, No.12, pp.7524-7533 (2015)

(15) M. Dal and R. Teodorescu: "Disturbance Observer Based Current controller for Vector Controlled IM Drives", 2008 IEEE Power Electronics Specialists Conference, pp.2621-2625 (2008)

(16) Y. Kim, K. kim, and S. Kim: "A Novel Disturbance Observer Based Robust Current-Control for a PMSM Drive System”, 54th IEEE Conference on Decision and Control, pp.6043-6046 (2015)

(17) H. Haga, K. Sayama, K. Ohishi, and T. Shimizu: "Current Control System Based on Repetitive Control and Disturbance Observer", Industrial Electronics Society, IECON 2015-41st Annual Conference of the IEEE, pp.004370004375 (2015)

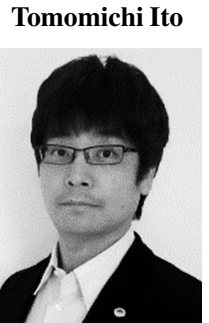

(Member) was born in 1976. He received the B.E. and M.E. from Hokkaido University in 1998 and 2000 respectively. In 2000, he joined Hitachi Ltd. and started to work as a researcher till March 2013. From April 2013 till March 2016, he worked as a design engineer of design department in the same company, and restarted research job from April 2016. His main interest is on grid connected large-scale converter systems. He is also a member of IEEE

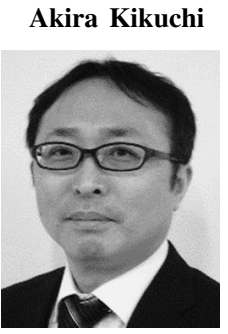

(Member) was born in 1972. He received the B.E. and M.E. from Kyoto University in 1995 and 1997 respectively. In 1997, he joined Hitachi Ltd. and had been working as a researcher. He worked on wind turbine generation systems, PV generation systems, drive system for damp truck. His current interest is grid-friendly technology for renewable energy sources. 
Masahiro Taniguchi (Non-member) was born in 1981. He received

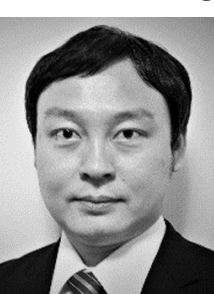
the B.E. and M.E. from Meiji University in 2005 and 2007 respectively. In 2007, he joined Hitachi Ltd. and started to work as a design engineer in Industrial Products Business Unit in Hitachi Ltd. He had developed several hundred $\mathrm{kW}$ PV inverters and power conditioning systems for battery energy storage systems.

Yoshitaka Takemoto (Non-member) was born in 1991. He received

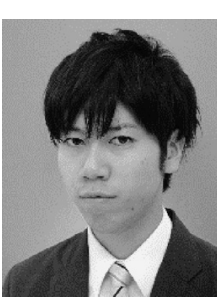
the B.E and M.E. from Mie University in 2013 an 2015 respectively. In 2015, he joined Hitachi Ltd. and started to work as a design engineer at Industrial Products Business Unit in Hitachi Ltd. He had developed PV inverters for mega solar projects. He is also working on the system control system of PV power plants.
Masaya Ichinose (Member) was born in 1969. He received the B.E.

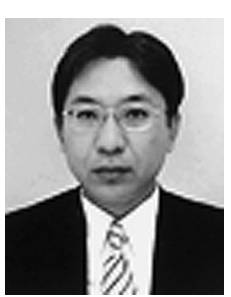
and M.E. from Shinshu University in 1993 and 1995 respectively. In 1995, he joined Hitachi Ltd. and started to work as a researcher till March 2010. From April 2010, he had been working as a design engineer. $\mathrm{He}$ is now responsible for the development of PV inverters for mega solar projects, power conditioning systems for battery energy storage systems. 